\title{
Inherited Cardiac Arrhythmias
}

Diagnosis, Treatment, and Prevention

Britt-Maria Beckmann, Arne Pfeufer, Stefan Kääb

\section{SUMMARY}

Background: The incidence of sudden cardiac death in persons under age 40 is roughly 3 per 100000 persons per year in Germany and North America. Many of these deaths are found to be due to hereditary heart diseases, often a primary structural heart disease associated with arrhythmia or else a primary arrhythmia syndrome in a structurally normal heart. Such diseases are usually of autosomal dominant inheritance, often affect otherwise healthy persons, and can generally be well treated if recognized early. Patients commonly have affected relatives who are still asymptomatic.

Methods: This review is based on articles up to May 2010 that were retrieved by a selective search of the Medline database via PubMed, with additional consideration of the relevant European and American guidelines and the German Law on Genetic Diagnosis.

Results and conclusion: Hereditary arrhythmia syndromes are now found in more than half of all initially unexplained cases of sudden cardiac death in young persons. Among such cases, the hereditary arrhythmia syndrome is primary in $70 \%$ and caused by an arrhythmogenic structural heart disease in $30 \%$. In addition to autopsy findings, a thorough family history, relevant medical findings obtained during life (if available), the examination of relatives, and directed molecular testing where appropiate enabled establishing the diagnosis. Arrthymia syndromes that can cause sudden death are often detectable during life if physicians and the public are appropriately sensitized.

\section{- Cite this as:}

Beckmann BM; Pfeufer A, Kääb S: Inherited cardiac arrhythmias: diagnosis, treatment and prevention. Dtsch Arztebl Int 2011; 108(37): 623-34. DOl: 10.3238/arztebl.2011.0623

Medizinische Klinik und Poliklinik 1, Ludwig-Maximilians-Universität München Dr. med. Beckmann, Prof. Dr. med. Kääb

EURAC Institut Bozen: Dr. med. Dipl.-Biochem. Pfeufer
H ereditary arrhythmia syndromes are rare, but early diagnosis can markedly reduce the risk of sudden cardiac death. This is the more important because those affected are often young, otherwise healthy people. This article will give an overview of the current diagnostic and therapeutic options.

\section{Learning objectives}

The aims of this article are to

- enable the reader to recognize signs and risk factors that should prompt suspicion of a congenital arrhythmia syndrome,

- describe what can be achieved with molecular genetic diagnostic tests,

- list the difficulties and limitations of interpreting genetic results,

- explain the treatment options, and

- list measures to prevent sudden cardiac death.

Among the hereditary arrhythmia syndromes a distinction is made between primary structural heart disease with increased arrhythmia risk and primary arrhythmia syndromes caused by dysfunction of the ion channels of the cardiac muscle (ion channel disease) (1-4). Although rare, because of their possibly fatal consequences it should not be left to cardiologists alone to recognize these diseases and the fact that they can be treated.

Among the most frequent structural changes that can be hereditary are hypertrophic obstructive and nonobstructive cardiomyopathy $(\mathrm{H}[\mathrm{O}] \mathrm{CM})$, arrhythmogenic right-ventricular cardiomyopathy/dysplasia (ARVC/D), dilated cardiomyopathy (DCM), and noncompaction cardiomyopathy.

The most common ion channel diseases are long-QT syndrome (LQTS), catecholaminergic polymorphous ventricular tachycardia (CPVT), Brugada syndrome, and short-QT syndrome (SQTS). These diseases can become manifest at any age. The genetic structural

\section{Hereditary arrhythmia syndromes}

These are rare diseases. However, early diagnosis can greatly reduce the risk of sudden cardiac death. 
Management of the most common hereditary arrhythmia syndromes* ${ }^{* 1}$

\begin{tabular}{|c|c|c|}
\hline Syndrome and lifestyle changes & Pharmacotherapy & $\begin{array}{l}\text { Implantable cardioverter defibrillator (ICD) for } \\
\text { high-risk patients }\end{array}$ \\
\hline $\begin{array}{l}\text { LQTS (class I, evidence level B) } \\
\text { - Avoid certain drugs } \\
\text { - No competitive sports } \\
\text { - Bring down fever early } \\
\text { - Avoid electrolyte disturbances (hypokalemia, } \\
\text { hypomagnesemia) } \\
\text { - Carry an emergency card } \\
\text { - Consider changes to worklife if appropriate }\end{array}$ & $\begin{array}{l}\text { - Beta-blockers } \\
\text { - In patients with prolonged QTc (class I, } \\
\text { evidence level B) } \\
\text { - In patients with normal QTc (class Ila, } \\
\text { evidence level B) } \\
\text { In some individual cases: } \\
\text { - Mexiletine plus beta-blockers for LQTS } 3 \\
\text { - (In some individual cases ranolazine or } \\
\text { flecainide plus beta-blockers) }\end{array}$ & $\begin{array}{l}\text { (With beta-blockers) } \\
\text { - Patients who have survived sudden cardiac } \\
\text { death (class I, evidence level A) } \\
\text { - Symptoms persisting despite therapy (class Ila, } \\
\text { evidence level B) }\end{array}$ \\
\hline $\begin{array}{l}\text { Catecholaminergic polymorphous ventricular tachycardia } \\
\text { - See LQTS }\end{array}$ & $\begin{array}{l}\text { - Beta-blockers (class I, evidence level C), } \\
\text { in some individual cases flecainide (plus } \\
\text { beta-blockers) }\end{array}$ & $\begin{array}{l}\text { (With beta-blockers) } \\
\text { - Patients who have survived sudden cardiac } \\
\text { death (class I, evidence level C) }\end{array}$ \\
\hline $\begin{array}{l}\text { Brugada syndrome (consensus report) } \\
\text { - Avoid certain drugs } \\
\text { - No competitive sports } \\
\text { - Bring down fever early } \\
\text { - Avoid electrolyte disturbances (hypokalemia, } \\
\text { hypomagnesiemia) } \\
\text { - Carry an emergency card } \\
\text { - Consider changes to worklife if appropriate }\end{array}$ & $\begin{array}{l}\text { - Quinidine in patients with electrical storm } \\
\text { (class Ilb, evidence level C) } \\
\text { - Quinidine may also be given prophylacti- } \\
\text { cally in the context of clinical studies }\end{array}$ & $\begin{array}{l}\text { - Patients who have survived sudden cardiac } \\
\text { death (class I, evidence level C) } \\
\text { - In patients with type } 1 \text { ECG and unexplained } \\
\text { syncope (class Ila, evidence level C) } \\
\text { - In patients with type } 1 \text { ECG and ventricular } \\
\text { tachycardia (class Ila, evidence level C) }\end{array}$ \\
\hline $\begin{array}{l}\text { Arrhythmogenic right ventricular cardiomyopathy } \\
\text { - No competitive sports }\end{array}$ & $\begin{array}{l}\text { - Sotalol (class lla, evidence level C), or } \\
\text { amiodarone or beta-blockers }\end{array}$ & $\begin{array}{l}\text { - As primary prophylaxis after persistent ventricu- } \\
\text { lar tachycardia/ventricular fibrillation despite opti- } \\
\text { mal pharmacotherapy (class I, evidence level B) } \\
\text { - As primary prophylaxis in patients with extensive } \\
\text { structural changes, one or more affected family } \\
\text { members, or unexplained syncope despite phar- } \\
\text { macotherapy (class lla, evidence level C) }\end{array}$ \\
\hline $\begin{array}{l}\text { Dilated cardiomyopathy } \\
\text { - No competitive sports }\end{array}$ & $\begin{array}{l}\text { - ACE inhibitors and beta-blockers (diure- } \\
\text { tics, aldosterone antagonists, AT1-block- } \\
\text { ers): treatment for cardiac insufficiency } \\
\text { - Amiodarone may be given for persistent } \\
\text { ventricular tachycardia (class llb, evi- } \\
\text { dence level C) }\end{array}$ & $\begin{array}{l}\text { (Extract from the indication list) } \\
\text { - Significant LV dysfunction and persistent intoler- } \\
\text { able VT/NF despite optimal pharmacotherapy } \\
\text { (class I, evidence level A) } \\
\text { - LVEF<35\% despite optimal pharmacotherapy in } \\
\text { patients with NYHA II-III (class I, evidence level } \\
\text { B) and patients with NYHA I (class Ilb, evidence } \\
\text { level B) }\end{array}$ \\
\hline $\begin{array}{l}\text { Hypertrophic cardiomyopathy } \\
\text { - No competitive sports } \\
\text { - No isometric exercise }\end{array}$ & $\begin{array}{l}\text { - Beta-blockers (if contraindicated, in some } \\
\text { individual cases calcium antagonists) }\end{array}$ & $\begin{array}{l}\text { - In patients with persistent VT/VF despite optimal } \\
\text { pharmacotherapy (class I, evidence level B) } \\
\text { - } 1 \text { or more "major risk factors" despite optimal } \\
\text { therapy (class Ila, evidence level C) }\end{array}$ \\
\hline
\end{tabular}

${ }^{* 1}$ Adapted from (10 and 21); LQTS, long QT syndrome; VT, ventricular tachycardia; VF, ventricular fibrillation; LVEF, left-ventricular ejection fraction; LV, left-ventricular

\section{Structural diseases with risk of arrhythmia}

- Hypertrophic (obstructive) cardiomyopathy (HOCM, HCM)

- Dilated cardiomyopathy (DCM)

- Arrhythmogenic right-ventricular cardiomyopathy/dysplasia (ARVC/D)
Primary arrhythmia syndromes

- Long-QT syndrome (LQTS)

- Catecholaminergic polymorphous ventricular tachycardia (CPVT)

- Brugada syndrome 
cardiac diseases, too, sometimes remain undiagnosed until an advanced age. With each of these diseases, which usually follow an autosomal dominant pattern of inheritance, the pathological genotype is not always expressed in the phenotype. Even where the genotype is identical, the disease itself may vary within a family. Clinical findings are not always unambiguous. For example, in 513 genetically affected relatives in LQTS families, it was shown that although the average frequency-corrected QT interval (QTc) was slightly prolonged $(454 \pm 43 \mathrm{~ms})$, half of the patients showed a normal QTc (5). In Brugada syndrome, in many patients a pathological ECG is visible only intermittently.

\section{Clinical symptoms}

Typical first symptoms are palpitations, brief losses of consciousness with spontaneous recovery (fainting/ syncope), or seizures caused by arrhythmias (arrhythmogenic seizures), especially if these are set off by specific triggers. The triggers may vary according to the disease. Typical of the most frequent forms of LQTS and CPVT is syncope during, for example, physical effort, swimming, or in psychological stress situations, after sudden noises (e.g., alarm clock), or after taking potentially repolarization-delaying medications (6-9).

In Brugada syndrome, arrhythmias tend to occur during sleep or with pyrexia (10). The primarily structural cardiac diseases with arrhythmia also often manifest for the first time not in the form of reduced tolerance of stress, but in arrhythmias.

Pathognomonic changes may be visible in the resting ECG (Figure 1). In most patients with LQTS, the frequency-corrected QT interval (QTc) is borderline to prolonged, or shows an abnormal T-wave morphology (e.g., notched, biphasic). In CVPT the resting ECG is typically normal; only in the stress ECG do frequent ventricular extrasystoles appear. In Brugada syndrome, a right bundle branch block-type deformation of the QRS complex in the form of a so-called Brugada type 1, 2, or 3 ECG may appear spontaneously or with pyrexia (Box 1). The cardiomyopathies (hypertrophic, arrhythmogenic right-ventricular, dilated, or noncompaction) sometimes manifest in the resting ECG with nonspecific repolarization disturbances; ARVC typically with T-wave inversions in leads V1 to V3 (after 14 years of age) and/or an epsilon potential. In LQTS, the high-grade arrhythmia underlying the symptoms is usually a specific polymorphous ventricular tachycardia (of the torsade de pointes type in which the QRS complexes seem to spiral around the isoelectric line); in Brugada syndrome it is a polymorphous ventricular tachycardia. In CPVT a bidirectional tachycardia, showing alternating QRS polarity, is typically causative of the symptoms, while in ARVC it is usually a monomorphous left bundle branch block-type ventricular tachycardia. There are no specific forms of ventricular tachycardia in the other cardiomyopathies. All the arrhythmias described here are often self-limiting, but can develop into ventricular fibrillation.

In rare cases the arrhythmia syndrome is accompanied by other abnormalities, such as the autosomal recessive hereditary Jervell and Lange-Nielsen syndrome with congenital hearing impairment, or Andersen syndrome (LQTS7) with sporadic muscle weakness, low-set ears, syndactyly, and other morphological abnormalities.

\section{Epidemiology}

The prevalence of the diseases described here ranges from $1: 500$ (HCM) through $1: 1000$ (ARVC) to $1: 2000$ (LQTS, CPVT, Brugada syndrome) or $1: 2500$ (DCM) (9-11).

Today it is assumed that about $90 \%$ of hypertrophic cardiomyopathies are inherited; in about $60 \%$ of cases a causative mutation in genes encoding sarcomere proteins is found. In about $40 \%$ of patients with ARVC a mutation is found in one of the genes for desmosomal proteins. In the case of LQTS and CPVT, in $60 \%$ to $70 \%$ of cases a mutation is found in the five genes that most often cause LQTS, which encode cardiac potassium or sodium channels; for CPVT it is the RYR2 gene, which encodes the calcium release channel in the cardiac sarcoplasmic reticulum. In dilated cardiomyopathy, a familial form of the disease is seen in about $30 \%$ of patients. In this case the hit rate for identifying a causative mutation is currently around $30 \%$. In Brugada syndrome, a causative mutation in the SCN5A gene, which encodes the cardiac sodium channel, is detected in about $26 \%$ of cases (Box 1 ). In all of these diseases, failure to identify a mutation by no means rules out (familial) disease; in the end it is always a clinical diagnosis. Genetic diagnostic techniques do contribute greatly to confirming the diagnosis, however, and in some cases also to genotype-based therapies. They also allow targeted examination of relatives who could potentially be affected.

\section{Clinical symptoms}

Typical first symptoms are palpitations, brief loss of consciousness with spontaneous recovery, or arrhythmogenic seizures, especially if these have specific triggers.

\section{Epidemiology}

The current estimated prevalence of the diseases under discussion ranges from

$1: 500$ (HCM/HOCM) through

$1: 2000$ (LQTS, CPVT) to

$1: 2500$ (DCM) 
Figure 1:

a) Long QT syndrome, type 1: prolonged QTC (485 ms), broadbased T waves.

b) Brugada type 1, 2, and 3 ECGs:

Type 1 ECG:

Coved-type ST elevation $\geq 2 \mathrm{~mm}$ with T-wave inversion in at least two of leads V1 to V3.

Type 2 ECG:

Saddle-back ST elevation with increased descent $\geq 2 \mathrm{~mm}$ and at least $1 \mathrm{~mm}$, elevation of the ST segment.

Type 3 ECG: Saddle-back or coved-type ST elevation

$<1 \mathrm{~mm}$.

c) Epsilon potential in a patient with arrhythmogenic rightventricular cardiomyopathy

d) Catecholaminergic polymorphous ventricular tachycardia. Above: Normal resting ECG.

Below: Frequent ventricular extrasystoles during exercise

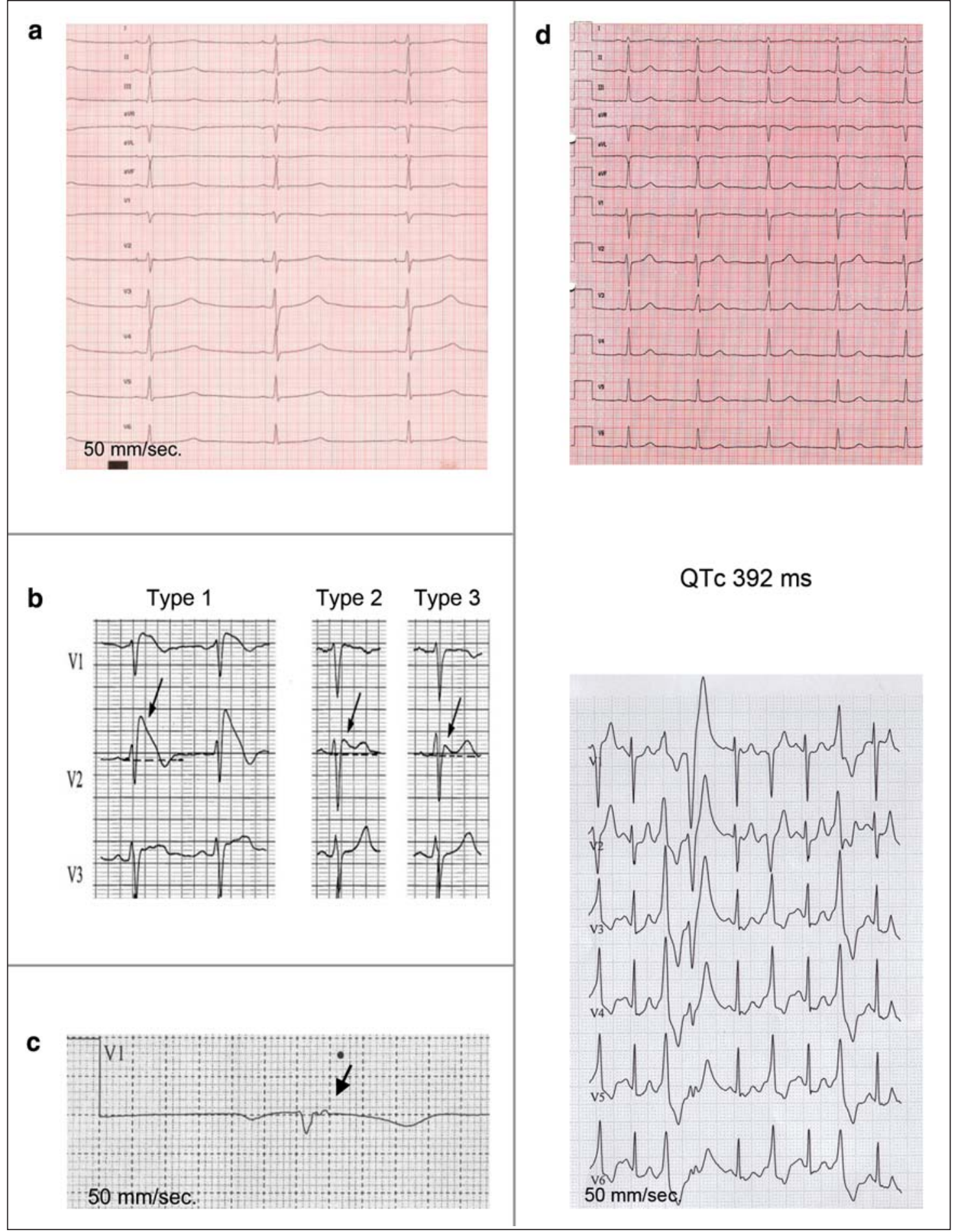

\section{Risk factors are:}

- Unexplained sudden death of young members of the family

- Other relatives with incidents of syncope of unknown etiology

- ECG abnormalities that have no other explanation
ECG abnormalities that have no other explanation are:

- Prolonged QT interval

- Ventricular extrasystoles on stress ECG

- ST segment elevation in the precordial leads

- Negative or abnormal T waves 


\section{Initial diagnostic procedure}

The initial diagnostic step is a 12-lead resting ECG, a stress ECG, a long-term ECG, and an echocardiographic examination. This should be followed by a thorough family history encompassing three generations. The patient should be asked explicitly about any cases of sudden death, incidents of syncope, or seizures. These noninvasive tests are often enough to allow a (suspected) diagnosis (Figure 1, Box 2).

\section{Indications for further diagnostic procedures}

Cases of sudden death at a young age among relatives, incidents of syncope, documented arrhythmias, or atypical epilepsy in the context of specific triggers should all prompt further investigation. A clinical evaluation is the first step towards determining the probability that a hereditary arrhythmia syndrome exists (Figures 1 and 2). If there is reason to suspect that it does, genetic testing should be carried out for confirmation. If a pathogenic mutation is documented in the patient, this information can be used for diagnostic or predictive genetic testing of relatives $(2,5)$.

\section{Further clinical diagnostic procedures}

If Brugada syndrome is suspected (Brugada type 2 or type 3 ECG), a 12-lead resting ECG in which the electrodes for leads V1 and V2 are placed one intercostal space higher can increase the sensitivity. A provocation test with ajmaline can unmask a hidden diagnostic Brugada type 1 ECG (10). In most of the diseases under discussion here, electrophysiological examination looking for whether ventricular tachycardia can be induced is of no confirmed documented use, but in individual cases it can be useful in showing up conduction disturbances. If a structural heart disease is suspected, magnetic resonance imaging can add information (Figure 2). The importance of genetic diagnostics varies between the different diseases. It is very useful to confirm a diagnosis of LQTS or CVPT, and can help in risk stratification in the familial cardiomyopathies (e.g., there is a higher risk when a mutation of the LMNA gene is present).

\section{Genetic diagnostic testing}

For all the (suspected) diagnoses described here, molecular genetic testing can be carried out. The genes most often involved, which are worth investigating and can at present be tested routinely, are listed in Box 1 . Other genes, if suspected, can be tested on an individ-

\section{Most common hereditary arrhythmia syndromes and current practicable and worthwhile genetic testing*}

- Primary familial arrhythmia syndromes (ion channel diseases):

- Long-QT syndrome: KCNQ1, KCNH2, SCN5A, KCNE1, KCNE2 (65\%)

- Brugada syndrome: SCN5A (25\% to 30\%)

- Catecholaminergic polymorphous ventricular tachycardia: RYR2 (60\%), possibly CASQ2

- Arrhythmogenic right-ventricular cardiomyopathy: PKP2, DSP, DSG2 (60\%)

- Short-QT syndrome: KCNH2, KCNJ2, KCNQ1

- Structural cardiac diseases with arrhythmia (cardiomyopathies):

- Hypertrophic (obstructive) cardiomyopathy: MYH7, MYBPC3, TNNT2 (60\%)

- Arrhythmogenic right-ventricular cardiomyopathy: PKP2, DSP, DSG2 (60\%)

- Familial dilated cardiomyopathy (DCM): LMNA, MYH7, TNNT2, SCN5A (20\% to $30 \%)$

- Left-ventricular noncompaction: MYH7, TAZ, LDB3

${ }^{{ }^{1}}$ Figures in parentheses represent clinical sensitivity, i.e., the percentage of patients who have the disease in whom positive results are found

ual case basis at specialist laboratories or as part of scientific projects (further information at www.ncbi. nlm.nih.gov/sites/GeneTests).

When the causative genotype is identified in a patient, there is an option to carry out diagnostic or predictive genetic testing in at-risk persons among the patient's relatives. For autosomal-dominant inheritance, this means testing the first-degree relatives of the symptomatic person following a step-wise or "cascade" pattern; for autosomal-recessive inheritance (e.g., Jervell and Lange-Nielsen syndrome) the siblings of the symptomatic person may be tested first. Ruling out the presence of the familial mutation or the causative genotype can reassure an at-risk person and usually makes further clinical investigations unnecessary. If the familial risk constellation is demonstrated in relatives, the general preventive measures and, if appropriate, medical therapy are recommended (Table). For both diagnostic and predictive genetic testing, the stipulations of the German Genetic Diagnostics Law must be observed.
Initial diagnostic procedure

- 12-lead resting ECG

- Stress and long-term ECG and echocardiographic examination

\section{Targeted genetic testing}

This is often practicable and is helpful to confirm a clinical suspicion. Generalized screening of all potential risk genes for sudden cardiac death is not worthwhile and usually adds little new information. 


\section{Grounds for suspicion for the various inherited cardiac arrhythmia disorders}

- The following are grounds to suspect long-QT syndrome if structural causes have been ruled out:

- Prolonged QT interval ( $ぇ \geq 440 \mathrm{~ms} ;$; $\geq 460 \mathrm{~ms}$ )

- (Standardized, extensive!) family history positive for syncope incidents, seizures, sudden cardiac death

- Abnormal T wave morphology (notched, widened, flattened, biphasic, negative)

- Documented torsades de pointes

- Index patient's history: syncope, seizures, palpitations

- Pathological QTc during stress or exercise

- Arrhythmias in the context of specific triggers (e.g., swimming, loud noises, medical drugs)

- The following are grounds to suspect catecholaminergic polymorphous ventricular tachycardia if structural causes have been ruled out:

- Index patient's history: syncope, seizures, palpitations in response to adrenergic stimulation

- Normal resting ECG, or there may be marked bradycardia

- Family history positive for syncope incidents, seizures, sudden cardiac death

- Occurrence of frequent polymorphous ventricular extrasystoles in stress ECG

- The following are grounds to suspect Brugada syndrome if structural causes have been ruled out:

- Brugada type 1, 2, or 3 ECG

- Family history positive for syncope incidents, seizures, sudden cardiac death

- Index patient's history: syncope, seizures, palpitations

- Arrhythmias in the context of specific triggers (pyrexia, after a large meal, after drinking alcohol)

\section{Problems in interpreting test results}

A "negative" search result for a mutation never rules out a well-founded clinical diagnosis. The sensitivity of the tests offered for routine investigation at present is around $26 \%$ to $70 \%$. If a result is positive, its plausibility must still be tested, since it may be that the mutation identified is not the cause - or not the sole cause - of the disease (12).

Without a suspected diagnosis, there is no point in carrying out a general genetic test ("to screen for every known gene that is known to be associated with sudden cardiac death"). Such screening often finds variants or even mutations that were not causative of the disease in the particular case, and thus can easily result in a misdiagnosis, which in turn would lead to false worry, or a false sense of security, in other relatives.

Even where there is a very definite suspected diagnosis, sometime a finding cannot be correctly interpreted without genetic and clinical testing of relatives, especially if the mutation in question is hitherto unknown. This often happens. Moreover, in about 5\% of cases there are two mutations present in one gene or different genes. In addition, the same mutation can result in different phenotypes even within one family (e.g., for the SCN5A mutations: LQTS 3, Brugada syndrome, cardiac conduction disease, atrial fibrillation, or DCM) $(14,15)$.

Another difficult situation in interpreting results is when a frequent genetic variant (polymorphism) is found that basically accords well with the phenotype but does not explain the severity of the disease. Sometimes it is not discovered until years later that a mutation believed to have caused the disease was actually an irrelevant polymorphism. For none of the diseases discussed here can a genetic test result predict whether a patient will develop symptoms or what the course of the disease will be. However, in most cases presymptomatic treatment and the avoidance of specific triggers can influence the course of the disease.

\section{Legal obligations}

The German Genetic Diagnostics Law must be observed in all diagnostic and predictive genetic testing.

\section{Interpretation of results}

A "negative" result of a mutation search never rules out a diagnosis that has been suspected on clinical grounds. The sensitivity of the tests offered routinely at present is around $26 \%$ to $70 \%$. 


\section{Psychosocial aspects of genetic testing}

The psychosocial stress of being diagnosed with an inherited disease varies greatly. Patients who have already been suffering from symptoms for which no disease could be identified are often relieved to have a diagnosis and the targeted treatment that a diagnosis makes possible. This is particularly true of the ion channel diseases, which are not progressive, and especially the most frequent LQTS types 1 and 2, which are well treatable.

The asymptomatic relatives who hear of the diagnosis react very variously. Reactions range from positive dealing with a disease that basically is treatable to fear that is hard to make an impression on. Psychotherapeutic counseling is often difficult in these cases, since it is not a matter of persuading the patient that any symptoms he or she experiences are harmless. In addition, in some cases these patients have already lost a relative to this disease. In this situation there is certainly an urgent need for a suitably trained therapist. Children seem to have fewer problems with the disease and better coping strategies, unless they have already lost a close relative to the disease. The better children had the disease explained to them, and how they could influence its course themselves, the better they coped $(16,17)$. However, the case is often different with the primary structural diseases, which are progressive, and for which the utility of prophylactic treatment is not always unambiguous. Asymptomatic mutation carriers should refrain from taking part in intensive sports activities. In such cases the question of whether to carry out presymptomatic genetic testing should be considered particularly carefully. This does not always result in relief for unaffected relatives, as has often wrongly been assumed, but can lead to severe psychological stress for them, with feelings of guilt and sympathy with the affected family members.

\section{German Genetic Diagnostics Law}

The German law on genetic testing, the Genetic Diagnostics Law (Gendiagnostikgesetz, GenDG) came into effect on 1 February 2010. This law aims to "set the preconditions for genetic testing and to prevent disadvantage occurring on the basis of genetic qualities, in order to maintain in particular the statutory obligation to respect and protect human dignity and the right to informational self-determination" ( 11 GenDG).

This law regulates, among other things, who may undertake the genetic counseling before and after

\section{FIGURE 2}

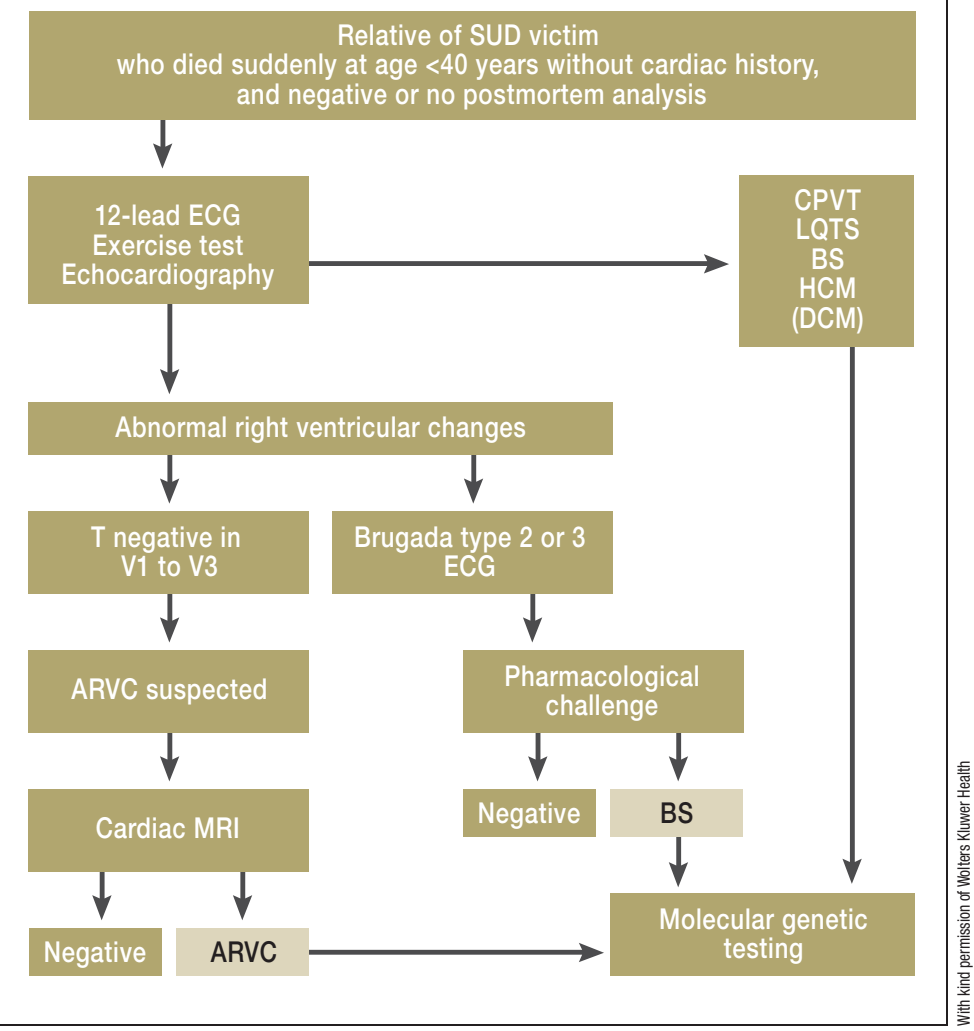

Algorithm for identification of familial disease from analysis of relatives of sudden cardiac death victims. Modified according to Tan et al., Circulation 2005 (3). SUD, sudden unexplained death; BS, Brugada syndrome

genetic testing. The task of developing guidelines was passed to the Genetic Diagnostics Commission (Gendiagnostik-Kommission, GEKO). So far, genetic counseling in the context of genetic testing has been carried out predominantly by clinical geneticists or physicians with an additional specialization in clinical genetics. This was not clearly regulated, however, and there was a danger that, as genetic testing became more available, it would take place without proper explanation and counseling carried out by appropriately trained persons.

Thus, since 1 February 2010, only physicians are allowed to order diagnostic genetic tests, and genetic counseling should be offered when the result is known; for predictive genetic tests, counseling by a clinical

\section{Psychosocial aspects}

Patients who have already been suffering from symptoms that could not be linked to any disease are often relieved to receive a diagnosis and the targeted treatment that the diagnosis makes possible.

\section{Results in children}

Children appear to have fewer problems in dealing with the disease; they seem to have better coping strategies. The better children had the disease explained to them, and how they could influence it, the better they came to terms with it. 
geneticist (or alternatively a physician with an additional specialization in clinical genetics) must be offered before and after the test is carried out. From 1 February 2012, this genetic counseling will also be able to be carried out by appropriately qualified physicians as part of their work within their own specialty, once they have obtained a qualification in "specialty-related genetic counseling." Aspects of genetic counseling that go beyond this will continue to be reserved for clinical geneticists or physicians with an additional specialization in clinical genetics. The responsible physician who has undertaken the counseling must document what was said in the counseling. Genetic counseling by a physician qualified for this task is not the same as patient information given in the course of obtaining informed consent, but goes far beyond this in terms of required content and the time required to be taken over it. (Sources: German Genetic Diagnostics Law of 31 July 2009 and GEKO Guideline on the Requirements for Qualification for and Content of Genetic Counseling according to $\S 23$, section 2 , no. $2 \mathrm{a}$ and $\S 23$, section 2 , no. 3 GenDG as formulated on 28 January 2011).

\section{Treatment and prevention}

The Table gives an overview of the preventive and therapeutic options, following the guidelines of the specialist medical societies of Europe and the USA. The details of the various treatments are not the main topic of this review article, and so the authors make no claim that the information in the table is complete. The decision to institute each therapeutic recommendation is to be made after careful consideration in each individual case. Most of the available data originate in register studies or case reports. Randomized studies are not available and probably never will be.

\section{Lifestyle}

In all cases, the recommendations about a particular lifestyle are of central importance. There are concrete preventive measures to take to avoid specific triggers, and patients must be informed about these. Ideally this will result in the affected persons' feeling that they can to some extent control the severity of their disease themselves. Generally recognized preventive measures for persons with asymptomatic carrier status are to avoid intensive physical activities, especially competitive ones, since these increase the risk that cardiac arrhythmias will occur and can have a negative influence on the disease course. Moderate physical activity is usually allowed and indeed desired (18). Specific, genotype-related preventive measures are:

- No competitive sports (valid for all arrhythmia syndromes)

- Don't go swimming alone and don't jump into cold water (especially LQTS1 and CPVT)

- Avoid sudden loud noises (LQTS2)

- Don't take potentially QT-prolonging medications (see www.qtdrugs.org) (all forms of LQTS)

- Avoid medications that are contraindicated for Brugada syndrome (www.brugadadrugs.org).

Pyrexia is a risk factor for arrhythmias in both LQTS and Brugada syndrome, and the fever should be brought down early, e.g., with paracetamol. This should be comprehensively explained to the person affected. Affected persons should always be given an up-to-date list of the typical risk factors for their disease. Those whose work involves a great deal of physical strain or potential danger to themselves or others if they should suffer syncope should consider a change of occupation.

\section{Pharmacotherapy}

Pharmacotherapy with beta-blockers is well established for LQTS and CPVT and is predominantly recommended both for symptomatic mutation carriers (secondary prophylaxis) and asymptomatic mutation carriers (primary prophylaxis) (19-21). In addition to the therapeutic measures described, there is the therapeutic option of left cardiac denervation in patients with refractory LQTS or those with CPVT.

\section{Medical devices}

In patients with LQTS in whom ventricular tachycardia occurs despite beta-blocker therapy and despite their following instructions about preventive measures, implantation of a defibrillator should be considered (21). For carriers of an SCN5A mutation, treatment should be decided on case-by-case basis. For all persons affected by this mutation there are specific preventive measures. The usefulness of prophylactic pharmacotherapy is less clear here (Table). In the structural heart diseases, the therapeutic utility for the patient of the genetic test result is much more limited. In this case the result is to be seen merely as one stone in the mosaic and usually has little influence on management. An exception to this is a mutation of the LMNA gene, which would lead to a lower threshold in recommending placement of an implantable cardioverter defibrillator (ICD) $(22,23)$.

\section{German Genetic Diagnostics Law}

This law regulates, among other things, who may carry out the genetic counseling before and after a genetic test.

\section{Advice on lifestyle changes}

Avoid intensive sports activities, particularly competitive ones. CPVT and LQTS: Don't go swimming alone; don't jump into cold water; keep your caffeine intake low; don't have a loud alarm clock next to your bed; if you run a temperature, take something to lower it quickly 
In DCM with complete bundle branch block and mild to moderate heart failure (NYHA class II and III) despite optimal pharmacotherapy, the current recommendation is for cardiac resynchronization therapy (CRT), with or without an ICD ("triple-chamber pacemaker" or "triple-chamber ICD"). In HCM with extensive symptoms with obstruction of the outflow tract, transcoronary ablation of septal hypertrophy (TASH) or surgical myectomy is often indicated. Patients with cardiomyopathy that remain refractory to treatment should be evaluated early enough with a view to a heart transplant. The prognosis of the diseases described here is usually good if they are recognized early enough and treated appropriately. This applies in particular to the primary arrhythmogenic diseases, in which life expectancy is not reduced in most cases so long as treatment is appropriate. In the structural forms of disease, the course is partly determined by the progression of the cardiac muscle changes, which can be very variable.

\section{Long-term care shared between family phy- sician, cardiologist, and specialist centers}

Family physicians are required, if one of their patients under the age of 60 dies suddenly and from unknown causes, to press for an autopsy and the taking of a blood sample. Family physicians should be in a position, on the basis of a thorough family history, to identify affected persons from families obviously at risk for sudden cardiac death. When the family or individual history suggests the possibility of an inherited cardiac arrhythmia disorder, the initial diagnostic procedure becomes very important. The first suspicion must usually be voiced by the family practitioner or the cardiologist to whom he or she refers. Any further necessary diagnostic tests (special imaging techniques, event recorder, invasive diagnostics), including whether molecular genetic testing would be worthwhile, should be decided on in close collaboration with a specialist center. Treatment decisions, regular treatment monitoring, and risk stratification should also be carried out regularly in close collaboration between family physician, cardiologist, and a specialist center throughout the life of the patient. Because these diseases are rare, and there is therefore a lack of large studies, risk stratification should be guided by guidelines issued by the national and international cardiological societies together with review articles and-equally important in the case of rare diseases - case reports and case series. Treatment with an ICD, which may appear to both patient and physician to be safest for the patient, should always be weighed up very carefully. The patient's quality of life can be greatly restricted by ICD-associated complications, which occur in up to $30 \%$ of ICD patients. In many cases, also, non-sustained ventricular tachycardia can lead to ICD shocks and thus in turn to catecholaminergically triggered tachycardia storms, especially in CPVT (24). It is extremely rare that implantation of an ICD is indicated merely on the basis of a genetic result. Because of the low prevalence of these diseases, in the long term major progress in treatment can only be made by collecting patients together in specialist centers and by international collaboration between such centers.

\section{Future perspectives}

In future, gene sequencing will be faster and available more cheaply (e.g., next-generation sequencing), so that in theory even large numbers of genes can be investigated simultaneously. This will not make recommendations for therapy any easier, as already, with only targeted sequencing of individual genes, variants and mutations are often found whose clinical significance is unclear. Thus, careful evaluation of genetic test results is becoming increasingly complex. Progress for patients will only come with "wise use and even wiser interpretation" of genetic testing in these potentially deadly, but treatable diseases (25).

\section{Conclusion}

A considerable percentage of inherited cardiac arrhythmias that can lead to sudden cardiac death at a young age can be recognized and effectively treated so long as the warning signs in the individual and family history are picked up and an ECG is carried out. Family physicians, pediatricians, cardiologists, anesthetists, neurologists, forensic medical specialists, and pathologists all have key roles in identifying at-risk patients and families. If there is reason to suspect the presence of an inherited cardiac arrhythmia disease, long-term collaboration between family physician, cardiologist, and specialist center is important, so that together they can establish an individualized diagnosis, systematic investigation and counseling of the family, and treatment decisions and risk determination. Comprehensive counseling for affected families, rigorous evaluation at regular intervals of the cardiac risk, and continual adjustment of therapy all contribute to reducing the incidence of sudden cardiac death in these families.

\section{Pharmacotherapy}

- CPVT and LQTS: Beta-blockers

- DCM: Treatment for heart failure

- Other diseases: Treatment decided on an individual basis

\section{Appeal to family physicians}

In all cases of sudden, unexplained death at an early age ( $<60$ years), family physicians should recommend autopsy and the taking of a blood sample. 


\section{GLOSSARY}

$\begin{array}{ll}\text { LQTS } & \text { Long-QT syndrome } \\ \text { CPVT } & \text { Catecholaminergic polymorphous ventricular tachycardia } \\ \text { ARVC/D } & \text { Arrhythmogenic right-ventricular cardiomyopathy/dysplasia } \\ \text { DCM } & \text { Dilated cardiomyopathy } \\ \text { H(O)CM } & \text { Hypertrophic (obstructive) cardiomyopathy } \\ \text { QTC } & \text { Frequency-corrected QT interval (usually calculated using Ba- } \\ & \text { zett's formula: QTC = QT in milliseconds/VRR interval before } \\ & \text { the measured QT time in seconds) } \\ \text { ICD } & \text { Implantable cardioverter defibrillator } \\ \text { CRT } & \text { Cardiac resynchronization therapy (special pacemaker for the } \\ & \text { treatment of patients with restricted pump function and dyssyn- } \\ & \text { chronous contraction pattern) } \\ \text { NYHA classes } & \text { Classification of cardiac function published by the New York } \\ & \text { Heart Association, dividing heart failure into various classes } \\ \text { VT } & \text { based on how much patients are limited during physical activity } \\ \text { VF } & \text { Ventricular tachycardia } \\ \text { LVEF } & \text { Ventricular fibrillation } \\ \text { SQTS } & \text { Left-ventricular ejection fraction } \\ \text { GenD } & \text { Short-QT syndrome } \\ & \text { German Genetic Diagnostics Law (came into effect February 1, } \\ & \text { 2010) }\end{array}$

\section{Classification of recommendations and evidence levels *1 \\ - Recommentation:}

Class l: $\quad$ Evidence and/or general agreement that a given treatment or procedure is beneficial, useful, and effective.

Class II: $\quad$ Conflicting evidence and/or a divergence of opinion about the usefulness/efficacy of the given treatment or procedure.

Class Ila: Weight of evidence/opinion is in favor of usefulness/efficacy.

Class Ilb: Usefulness/efficacy is less well established by evidence/opinion.

Class III: $\quad$ Evidence or general agreement that the given treatment or procedure is not useful/effective and in some cases may be harmful.

\section{- Evidence level:}

A Data from several randomized studies or meta-analyses of adequate size

B Data from a randomized study or several large non-randomized studies

C Expert consensus opinion based on case reports or clinical experience

\footnotetext{
${ }^{* 1}$ Following the guidelines of the American College of Cardiology, the American Heart Association, and the European Society of Cardiology
}

\section{Conflict of interest statement}

Professor Kääb and Dr Beckmann received funding for the following research projects: ANR SCD Gene: $01 \mathrm{KU}$ 0907, $\mathrm{M}^{4}$ Innovative Therapiestrategien für Herzrhythmusstörungen; Drug Safety: 01 EX 1021 E, NGFN Plus: 01 GS 0838. Dr Pfeufer declares that he has no conflict of interest.

Manuscript submitted on 4 May 2011, revised version accepted on 4 July 2011.

\section{REFERENCES}

1. Kauferstein S, Kiehne N, Neumann T, Pitschner H, Bratzke H: Cardiac gene defects can cause sudden cardiac death in young people. Dtsch Arztebl Int 2009; 106(4): 41-7.

2. Behr ER, Dalageorgou C, Christiansen M, et al.: Sudden arrhythmic death syndrome: familial evaluation identifies inheritable heart disease in the majority of families. Eur Heart J 2008; 29: 1670-80.

3. Tan HL, Hofman N, van Langen IM, van der Wal AC, Wilde AA: Sudden unexplained death: heritability and diagnostic yield of cardiological and genetic examination in surviving relatives. Circulation 2005; 112: 207-13

4. Basso C, Burke M, Fornes P, et al.: Guidelines for autopsy investigation of sudden cardiac death. Virchows Arch 2008; 452: 11-8.

5. Hofman N, Wilde AA, Tan HL. Diagnostic criteria for congenital long QT syndrome in the era of molecular genetics: do we need a scoring system? Eur Heart J 2007; 28: 1399.

6. Ackerman MJ, Tester DJ, Porter CJ. Swimming, a gene-specific arrhythmogenic trigger for inherited long QT syndrome. Mayo Clin Proc 1999; 74: 1088-94.

7. Moss AJ, Robinson JL, Gessman L, et al.: Comparison of clinical and genetic variables of cardiac events associated with loud noise versus swimming among subjects with the long QT syndrome. Am J Cardiol 1999; 84: 876-9.

8. Schwartz PJ, Priori SG, Spazzolini C, et al.: Genotype-phenotype correlation in the long-QT syndrome: gene-specific triggers for life-threatening arrhythmias. Circulation 2001; 103: 89-95.

9. Vollmar C, Feddersen B, Beckmann BM, Kaab S, Noachtar S: Seizures on hearing the alarm clock. Lancet 2007; 370: 2172.

10. Antzelevitch C, Brugada P, Borggrefe M, et al.: Brugada syndrome: report of the second consensus conference: endorsed by the Heart Rhythm Society and the European Heart Rhythm Association. Circulation 2005; 111: 659-70.

11. Peters S, Trummel M, Meyners W: Prevalence of right ventricular dysplasia-cardiomyopathy in a non-referral hospital. Int J Cardio 2004; 97: 499-501.

12. Schwartz PJ, Stramba-Badiale M, Crotti L, et al.: Prevalence of the congenital long-QT syndrome. Circulation 2009; 120: 1761-7.

13. Beckmann BM, Wilde AA, Kaab S: Dual inheritance of sudden death from cardiovascular causes. N Engl J Med 2008; 358: 2077-8.

14. Olson TM, Michels W, Ballew JD, et al.: Sodium channel mutations and susceptibility to heart failure and atrial fibrillation. JAMA 2005 293: 447-54

15. Smits JP, Koopmann T, Wilders R, et al.: A mutation in the human cardiac sodium channel (E161K) contributes to sick sinus syndrome, conduction disease and Brugada syndrome in two families. J Mol Cell Cardiol 2005; 38: 969-81.

\section{Developments in therapy}

In the long term, the only way to achieve major progress in therapy will be through collecting patients in specialist centers and through international collaboration between these centers.
Reducing the incidence of sudden cardiac death

So long as physicians are sufficiently aware, a large percentage of inherited cardiac arrhythmia disorders can be diagnosed and treated effectively. 
16. Meulenkamp TM, Tibben A, Mollema ED, et al.: Predictive genetic testing for cardiovascular diseases: impact on carrier children. Am J Med Genet A 2008;146A: 3136-46.

17. Smets EM, Stam MM, Meulenkamp TM, et al.: Health-related quality of life of children with a positive carrier status for inherited cardiovascular diseases. Am J Med Genet A 2008; 146A: 700-7.

18. Corrado D, Basso C, Rizzoli G, Schiavon M, Thiene G: Does sports activity enhance the risk of sudden death in adolescents and young adults? J Am Coll Cardiol 2003; 42: 1959-63.

19. Schwartz PJ, Moss AJ, Vincent GM, Crampton RS: Diagnostic criteria for the long QT syndrome. An update. Circulation 1993; 88: 782-4.

20. Shimizu W: The long QT syndrome: therapeutic implications of a genetic diagnosis. Cardiovasc Res 2005; 67: 347-56.

21. Zipes DP, Camm AJ, Borggrefe M, et al.: ACC/AHA/ESC 2006 Guidelines for management of patients with ventricular arrhythmias and the prevention of sudden cardiac death: a report of the American College of Cardiology/American Heart Association Task Force and the European Society of Cardiology Committee for Practice Guidelines (writing committee to develop Guidelines for Management of Patients With Ventricular Arrhythmias and the Prevention of Sudden Cardiac Death): developed in collaboration with the European Heart Rhythm Association and the Heart Rhythm Society. Circulation 2006; 114: e385-484.

22. Beckmann B, Holinski-Feder E, Walter M, et al.: Laminopathy presenting as familial atrial fibrillation. Int J Cardiology 2010; 145: 394-6.

23. Meune C, Van Berlo JH, Anselme F, Bonne G, Pinto YM, Duboc D: Primary prevention of sudden death in patients with lamin $A / C$ gene mutations. N Engl J Med 2006; 354: 209-10.

24. Wilde AA, Bhuiyan ZA, Crotti L, et al.: Left cardiac sympathetic denervation for catecholaminergic polymorphic ventricular tachycardia. N Engl J Med 2008; 358: 2024-9.

25. Tester D, Ackerman M: Genetic testing for potentially lethal, highly treatable inherited cardiomyopathies/channelopathies in clinical practice. Circulation 2011;123:1021-37.

\section{Corresponding author}

Prof. Stefan Kääb

Medizinische Klinik und Poliklinik I, Klinikum der Universität München

Großhadern (LMU - Großhadern)

Marchioninistr. 15, 81377 München, Germany

stefan.kaab@med.uni-muenchen.de

\section{Further information on CME}

This article has been certified by the North Rhine Academy for Postgraduate and Continuing Medical Education.

Deutsches Ärzteblatt provides certified continuing medical education (CME) in accordance with the requirements of the Medical Associations of the German federal states (Länder). CME points of the Medical Associations can be acquired only through the Internet, not by mail or fax, by the use of the German version of the CME questionnaire within 6 weeks of publication of the article. See the following website: cme.aerzteblatt.de

Participants in the CME program can manage their CME points with their 15-digit "uniform CME number" (einheitliche Fortbildungsnummer, EFN). The EFN must be entered in the appropriate field in the cme.aerzteblatt.de website under "meine Daten" ("my data"), or upon registration. The EFN appears on each participant's CME certificate.

The solutions to the following questions will be published in issue 45/2011. The CME unit "Treatment of Tobacco Dependence" (issue 33/2011) can be accessed until 30 September 2011.

For issue 41/2011, we plan to offer the topic „Treatment Strategies in Gastric Cancer".

Solutions to the CME questionnaire in issue 28-29/2011: Wiegratz I, Thaler CJ: Hormonal Contraception-What Kind, When, and for Whom?

Solutions: 1e, 2b, 3a, 4a, 5c, 6e, 7b, 8e, 9d, 10d 


\section{Please answer the following questions to participate in our certified Continuing Medical Education program. Only one answer is possible per question. Please select the answer that is most appropriate.}

\section{Question 1}

How high is the current estimated prevalence of hereditary arrhythmia syndromes in the general population?
a) $1: 100$
b) $1: 500-1: 2500$
c) $1: 5000-1: 10000$
d) $3: 100000$
e) $1: 150000$

\section{Question 2}

Which symptom suggests the presence of an hereditary arrhythmia syndrome?

a) Increased incidents of orthostatic syncope

b) Syncope or seizures when swimming or on physical effort?

c) Frequent bouts of flu with high fever and dizziness

d) ECG showing T-wave inversion in leads V1 to V3 up to age 14

e) Positive family history of coronary heart disease

\section{Question 3}

What lifestyle change should be recommended to all patients with the three arrhythmia syndromes (LQTS, CPVT, and Brugada syndrome)?

a) Change of workplace to fresh air and physical labor

b) Avoid competitive sports

c) Long-term antibiotic therapy

d) Avoid caffeine

e) Don't have a loud alarm clock next to your bed

\section{Question 4}

How often does hypertrophic cardiomyopathy occur in a familial form?

a) In $10 \%$ of cases

b) In $20 \%$ of cases

c) In $30 \%$ of cases

d) In $40 \%$ of cases

e) In $90 \%$ of cases

\section{Question 5}

What should be the initial investigations recommended to a patient with a suspected hereditary arrhythmia syndrome?

a) Resting ECG, stress ECG, long-term ECG, and echocardiography

b) Resting ECG, long-term ECG, and genetic testing

c) Resting ECG, long-term ECG, and cardiac MRI

d) Resting ECG, echocardiography, and genetic testing

e) Resting ECG, stress ECG, and genetic testing

\section{Question 6}

What, for the carrier of a primary arrhythmia syndrome

(LQTS, Brugada syndrome, CPVT), is the most useful consequence of genetic testing?

a) Prediction of individual life expectancy

b) Diagnostic confirmation, because this contributes to individualized treatment recommendations and allows early diagnostic testing of relatives

c) Preventing conception (family planning)

d) Complete psychological relief for the family

e) Early application for an invalidity pension
Question 7

What new provisions came into effect with the German Genetic Diagnostics Law (GenDG) on 1 February 2010?

a) For predictive genetic testing, genetic counseling must be offered before and after the result

b) Diagnostic genetic testing need not necessarily be arranged by a physician; however, once the result is in, genetic counseling must be offered

c) Genetic counseling is equivalent to the information given to a patient during the informed consent process

d) From 1 February 2012, any physician may arrange for genetic testing and carry out genetic counseling

e) The aim of the GenDG, which came into effect on 1 February 2011, is to limit the right to informational self-determination (right to determine the disclosure and use of one's own personal data) in favor of the common good.

\section{Question 8}

What is the standard treatment for the most common types of LQTS (types 1 and 2)?

a) Beta-blockers, lifestyle adjustment, in some cases defibrillator implantation

b) Defibrillator implantation, so that beta-blockers and other preventive measures are unnecessary

c) Regular ingestion of potentially QT-lengthening drugs

d) Listing for heart transplant

e) No pharmacotherapy is required initially; beta-blockers should be started only after the occurrence of syncope incidents.

Question 9

After the initial diagnosis, who should be responsible for the care of affected families?

a) The family physician, if the disease remains asymptomatic

b) The (pediatric) cardiologist once symptoms occur

c) A specialist center when severe symptoms occur

d) Family physician, cardiologist, and specialist center together, even when the patient(s) remain(s) asymptomatic

e) After appropriate risk stratification and, if necessary, initiation of pharmacotherapy and avoidance of preventive measures, further examinations are only necessary if symptoms occur

Question 10

What will the expected future development of cardiological genetic testing look like?

a) As genetic testing becomes faster and more cheaply available, it will make treatment recommendations much easier

b) Because genetic testing will be more easily available, it will be possible to screen all genes known to be potentially related to sudden cardiac death and thus to produce an individual risk profile

c) General screening of the known "risk genes" for sudden cardiac death produces little useful information; what is worthwhile is to investigate specific individual genes on the basis of a clinical suspicion

d) Commercial companies offering "personalized genomics," which offer the creation of individual risk profiles over the internet, will in future make many clinical investigations unnecessary

e) In only a few years, we will be able to make a good prediction of the course of a disease on the basis of the existence of a given mutation. 